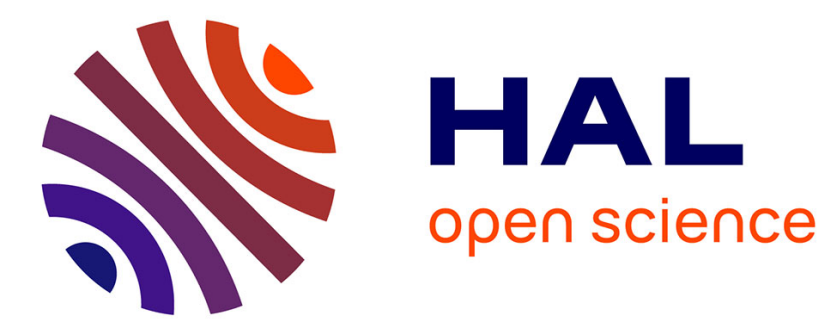

\title{
Iron limitation induces SpoT-dependent accumulation of ppGpp in Escherichia coli.
}

\author{
Daniel Vinella, Christian Albrecht, Michael Cashel, Richard d'Ari
}

\section{To cite this version:}

Daniel Vinella, Christian Albrecht, Michael Cashel, Richard d'Ari. Iron limitation induces SpoTdependent accumulation of ppGpp in Escherichia coli.. Molecular Microbiology, 2005, 56, pp.958-970. 10.1111/j.1365-2958.2005.04601.x . hal-00069437

\section{HAL Id: hal-00069437 \\ https://hal.science/hal-00069437}

Submitted on 8 Jun 2006

HAL is a multi-disciplinary open access archive for the deposit and dissemination of scientific research documents, whether they are published or not. The documents may come from teaching and research institutions in France or abroad, or from public or private research centers.
L'archive ouverte pluridisciplinaire HAL, est destinée au dépôt et à la diffusion de documents scientifiques de niveau recherche, publiés ou non, émanant des établissements d'enseignement et de recherche français ou étrangers, des laboratoires publics ou privés. 


\title{
Iron limitation induces SpoT-dependent accumulation of ppGpp in Escherichia coli
}

\author{
D. Vinella ${ }^{1}$, C. Albrecht ${ }^{1,2}$, M. Cashel ${ }^{3}$ and R. D'Ari ${ }^{1}$
}

${ }^{1}$ Institut Jacques Monod (C.N.R.S., Université Paris 6, Université Paris 7), 2 place Jussieu, 75251 Paris Cedex 05, France

${ }^{2}$ Present address: Ludwig-Maximillians-Universität, Lehrstuhl für angewandte Physik, Amalienstr. 54, 80799 Munich, Germany

${ }^{3}$ Laboratory of Molecular Genetics, National Institute of Child Health and Human

Development, National Institutes of Health, Bethesda, MD, 20892-2785 USA

Running Title: Iron starvation and ppGpp synthesis

*To whom correspondence should be sent. 


\section{Summary}

In Escherichia coli the $\beta$-lactam mecillinam specifically inhibits penicillin-binding protein 2 (PBP2), a peptidoglycan transpeptidase essential for maintaining rod-shape. We have previously shown that PBP2 inactivation results in a cell division block and that an increased concentration of the nucleotide ppGpp, effector of the RelA-dependent stringent response, confers mecillinam resistance and allows cells to divide as spheres in the absence of PBP2 activity. In this study we have characterized an insertion mutation which confers mecillinam resistance in wild type and $\Delta$ relA strains but not in $\Delta r e l A \Delta s p o T$ strains, devoid of ppGpp. The mutant has an insertion in the fes gene, coding for enterochelin esterase. This cytoplasmic enzyme hydrolyzes enterochelin- $\mathrm{Fe}^{3+}$ complexes, making the scavenged iron available to the cells. We show that inactivation of the fes gene causes iron limitation on rich medium plates and a parallel SpoT-dependent increase of the ppGpp pool, as judged by the induction of the iron-regulated $f i u:: l a c Z$ fusion and the repression of the stringently controlled $\mathrm{P} 1_{\text {rrn }}:$ :lacZ fusion, respectively. We further show, by direct ppGpp assays, that iron starvation in liquid medium produces a SpoT-dependent increase of the ppGpp pool, strongly suggesting a role for iron in the balance of the two activities of SpoT, synthesis and hydrolysis of (p)ppGpp. Finally, we present evidence that ppGpp exerts direct or indirect positive control on iron uptake, suggesting a simple homeostatic regulatory circuit: iron limitation leads to an increased ppGpp pool, which increases the expression of iron uptake genes, thereby alleviating the limitation. 


\section{Introduction}

The Gram negative bacterium Escherichia coli has evolved various adaptive mechanisms which enable it to respond rapidly to a large number of changes in its growth conditions. The stringent response is one such mechanism. In relA ${ }^{+}$cultures starved for a required amino acid the transcription of ribosomal and transfer RNA genes is severely limited and accumulation of stable RNA decreases markedly (Stent and Brenner, 1961; Cashel et al., 1996). This response depends on the ribosome-associated RelA protein, which, in the presence of an uncharged cognate tRNA in the ribosomal A site, pyrophosphorylates GTP to produce pppGpp, which is rapidly converted to ppGpp [guanosine 3'-pyrophosphate 5'-pyrophosphate (Wendrich et al., 2002)]. Co-crystallization studies have revealed that the nucleotide ppGpp binds RNA polymerase near the catalytic center in the secondary channel (Artsimovitch et al., 2004). Its binding is proposed to be stabilized by DksA, a GreA/GreB-like protein thought to stabilize bound ppGpp by weakening initiating NTP binding and destabilizing open promoter complexes (Perederina et al., 2004; Paul et al., 2004).

The ppGpp pool increases not only during amino acid starvation (the stringent response) but also after a number of other stresses, including starvation for carbon, nitrogen, phosphate or fatty acids (Murray and Bremer, 1996; Seyfzadeh et al., 1993; Spira et al., 1995; Villadsen and Michelsen, 1977). In most if not all cases, this increase is independent of RelA. It depends on the SpoT protein, which both synthesizes and hydrolyzes (p)ppGpp, and it is brought about by an altered balance of the SpoT synthetic and hydrolytic activities, even in the absence of RelA. The signal or regulator to which SpoT responds during SpoT-dependent ppGpp accumulation after various stresses remains unknown (see Cashel et al., 1996, for review). In the complete absence of SpoT, ppGpp will accumulate to levels that block ribosome synthesis and prevent cell growth when the RelA protein is present; $\Delta$ relA $\Delta$ spoT strains are viable and have no detectable ppGpp (Xiao et al., 1991).

In $E$. coli the $\beta$-lactam antibiotic mecillinam (Lund and Tybring, 1972) specifically inactivates penicillin-binding protein 2 (PBP2), a peptidoglycan transpeptidase essential for the maintenance of rod shape and cell elongation (Spratt, 1975; Spratt and Pardee, 1975; 
Spratt, 1977). When PBP2 is inactivated, either genetically or by mecillinam, the cells become spherical and, in the case of wild type strains in rich media, they die (Aono et al., 1979). We have shown that death results from a failure of the cocci to divide (Vinella et al., 1993), although PBP2 is not involved in the process of cell division. We further showed that division can be restored in the absence of PBP2 activity by a moderate increase of the ppGpp pool (Vinella et al., 1992; Joseleau-Petit et al., 1994). Under these conditions, the cells are resistant to mecillinam, growing and dividing as spheres. This seemed to provide a convenient selection for identifying regulators of SpoT activity. We therefore selected mecillinam resistant mutants of a $\Delta$ relA strain, able to grow in rich medium in the presence of the antibiotic. We report here the characterization of one such mutant obtained by random insertion mutagenesis. The mutant has an increased ppGpp pool. Molecular analysis shows that it is affected in iron uptake; the results suggest the involvement of iron in the regulation of SpoT activity.

Iron is an essential element, but in ærobic environments its acquisition poses a problem since ferrous ions are readily oxidized to ferric ions and ferric salts are generally insoluble at neutral $\mathrm{pH}$. To solve this problem, bacteria have evolved several mechanisms of iron uptake. The most efficient involves siderophores, small molecules with extraordinarily high affinity for ferric ions (see Earhart, 1996, for review). The E. coli siderophore enterochelin (or enterobactin) is synthesized in the cytoplasm by the ent gene products and secreted into the medium, where it scavenges ferric ions. The Ent-Fe ${ }^{3+}$ complex is then brought back into the cell via a specific uptake system (Fep). It is hydrolyzed by the product of the fes gene, enterochelin esterase, releasing the iron in the cytoplasm where it is reduced to $\mathrm{Fe}^{2+}$ (Earhart, 1996).

Other iron uptake systems of E. coli (Earhart, 1996) include the use of exogenous citrate, which can chelate $\mathrm{Fe}^{3+}$ ions and deliver them to a specific membrane transport system (the $\mathrm{Fec}$ system); a permease for $\mathrm{Fe}^{2+}$ ions (Feo); and specific transport systems for siderophores synthesized by other microorganisms (Fhu, Iut). The regulation of iron uptake is under negative control by the Fur protein, which, in the presence of its corepresssor $\mathrm{Fe}^{2+}$, represses the transcription of all genes involved in iron metabolism; Fur-Fe ${ }^{2+}$ also represses 
the expression of the small RNA RyhB (Masse and Gottesman, 2002; Masse et al., 2002), a translational repressor of genes coding for a number of iron-containing and iron storage proteins (Geissmann and Touati, 2004).

In the present work we analyze the connection between iron starvation and ppGpp levels. Our results indicate that iron limitation causes SpoT-dependent ppGpp accumulation, which in turn stimulates the cell's capacity to take up iron. This negative feedback loop provides homeostatic regulation of the internal iron concentration, mediated by the SpoT protein and the nucleotide ppGpp. 


\section{Results}

\section{Selection and characterization of a new mecillinam resistant mutant}

A simple selection for mecillinam resistant insertion mutants was described previously (Vinella et al., 2000). It was carried out with a mini-Tn $10\left(\mathrm{Cm}^{\mathrm{R}}\right)$ element in the $\Delta r e l A \Delta l a c Z$ $\mathrm{P} 1_{\text {rrnB }}:$ :lacZ strain CF6301. One of the mutants so isolated was mcr-14::cat. We backtransduced the $\mathrm{Cm}^{\mathrm{R}}$ determinant into strain CF6301 and verified that it was stable and that chloramphenicol and mecillinam resistance were 100\% cotransducible (Vinella et al., 2000), showing that the mecillinam resistant phenotype is indeed due to the mini- $\operatorname{Tn} 10\left(\mathrm{Cm}^{\mathrm{R}}\right)$ insertion. On LB plates the mcr-14::cat mutant cells grow and divide as spheres in the presence of mecillinam, as rods in its absence.

The ppGpp pool, normally low in rich media, was deduced to be increased in the mcr-14::cat mutant, as evaluated by the $\mathrm{P} 1_{r r n B}:: l a c Z$ fusion. This promoter of the ribosomal RNA operon $r r n B$ is under negative control by ppGpp. It had lower expression in the mcr-14::cat mutant than in the parental strain, as evidenced by a pale blue coloration of the colonies on LB plates containing X-Gal compared to darker blue for the parent (Vinella et al., 2000). Furthermore, unlike mecillinam resistant mutants affected in aminoacyl-tRNA synthetases (Vinella et al., 1992), the decreased expression of $\mathrm{P} 1_{r r n B}:: l a c Z$ in the mcr-14::cat mutant was RelA-independent since strain CF6301 is $\Delta$ relA. This suggested that SpoT activity was altered in the mutant or, alternatively, that the mutant cells were more sensitive then the parental strain to a given concentration of ppGpp.

In addition to its mecillinam resistance and decreased $P 1_{r r n}:: l a c Z$ expression, the mcr-14::cat mutant had several other phenotypes. On rich medium plates (LB or LB*, $c f$. Experimental Procedures) it formed smaller colonies than the parental strain, these colonies were pinkish-brown in color, and on M9 glucose plates it could barely grow, forming tiny colonies visible only after 3 days of incubation at $37^{\circ} \mathrm{C}$ and unable to grow further (Table 1). As described below, the mcr-14::cat mutation also increased the expression of a fiu::lacZ fusion, indicating iron limitation (Table 2B). 
The mcr-14::cat mutation, transduced into the isogenic relA ${ }^{+}$strain DV352, conferred a similar phenotype: mecillinam resistance on $\mathrm{LB}^{*}$ plates, lowered expression of the $\mathrm{P} 1_{r r n B}:$ :lacZ fusion on LB X-Gal plates, small pink colonies on LB plates and near absence of growth on M9 glucose plates.

\section{Identification of the mcr-14::cat mutation as a fes::cat allele}

To localize the mini- $\operatorname{Tn} 10\left(\mathrm{Cm}^{\mathrm{R}}\right)$ element present in the $m c r-14:: c a t$ mutant, we cloned the $c a t$ gene and flanking chromosomal DNA in the vector $\mathrm{pKS}+\left(\mathrm{Amp}^{\mathrm{R}}\right)$ (see Experimental Procedures). From an $\mathrm{Amp}^{\mathrm{R}} \mathrm{Cm}^{\mathrm{R}}$ transformant we extracted the plasmid DNA and sequenced it using the $\mathrm{CmD}$ and $\mathrm{CmF}$ primers. The insertion was found to interrupt the 359th codon (of 375) of the fes gene, coding for enterochelin esterase. The mcr-14::cat mutation was therefore renamed fes::cat.

The fes gene, coding for enterochelin esterase, is the first in an operon including the $e n t F$ and $f e p E$ genes, whose products are involved in enterochelin synthesis and the transport into the cells of the Ent-Fe ${ }^{3+}$ complex, respectively (Earhart, 1996). To determine whether the phenotypes of the fes::cat mutant were due to inactivation of the fes gene itself or to polar effects, we cloned just the wild type fes gene with its natural promoter in the vectors pBAD18 $\left(\mathrm{Km}^{\mathrm{R}}\right)$ and $\mathrm{pKS}+\left(\mathrm{Amp}^{\mathrm{R}}\right)$ (see Experimental Procedures), producing pDV51 and pDV52, respectively. We transformed the mecillinam resistant strain DV377 (fes::cat relA1) with pDV51 and showed that it became mecillinam sensitive on LB* plates. When pDV52 was introduced into strains CF6301 (fes::cat $\Delta$ relA $\mathrm{P} 1_{r r n B}:$ :lacZ $\Delta l a c Z$ ) and DV310 (fes::cat $\Delta$ relA fiu::lacZ $\Delta$ lacZ), it restored normal colony size on M9 glucose, LB and LB* plates and eliminated the pink coloration of the colonies on LB and LB* plates. The plasmid also restored a normal level of expression of the $\mathrm{P} 1_{\text {rrn } B}:$ :lacZ and fiu::lacZ fusions on LB and LB* plates containing X-Gal, as judged by the intensity of the blue coloration. In conclusion, all phenotypes of the fes::cat mutant were due to inactivation of the fes gene, not to polar effects on entF or fepE.

\section{Genetic and physiological analysis}


It seemed possible that the slow growth (small colony size) of the fes::cat mutant on rich medium plates reflected iron limitation, since the mutant is unable to use the enterochelin system, which is the cell's most efficient pathway of iron acquisition. We therefore looked at the effect on colony size of additives that increase iron availability. Indeed, citrate and ascorbate increased colony size on LB and LB* plates ( $c f$. Experimental Procedures); citrate activates the Fec system of iron uptake and ascorbate reduces ferric ions to $\mathrm{Fe}^{2+}$, which can then enter the cell via the Feo permease (Earhart, 1996). In the presence of ascorbate, a complete parental phenotype was restored (Table 1). The addition of $\mathrm{FeCl}_{3}(0.1 \mathrm{mM})$ also restored a parental phenotype; in contrast, the addition of $\mathrm{MgSO}_{4}, \mathrm{MnCl}_{2}, \mathrm{ZnSO}_{4}, \mathrm{CuSO}_{4}$ or $\mathrm{CoCl}_{2}$ (each $10 \mathrm{mM}$ ) did not improve the growth of the mutant on LB plates (data not shown).

These results are consistent with the hypothesis of iron limitation of the fes::cat mutant on rich medium plates. We next looked at the phenotypic effects of other mutations affecting iron uptake. The FepB protein specifically binds the Ent-Fe ${ }^{3+}$ complex in the periplasm, after it has crossed the outer membrane, and presents it to an inner membrane transporter that takes it into the cytoplasm; the FepC protein is one component of this transporter (Earhart, 1996). The $f e p B$ and $f e p C$ single mutants behaved similarly to the fes::cat mutant on rich medium and M9 glucose plates (Table 1), except that their colonies on LB plates, although small, lacked the pink coloration. The fes::cat fepB and fes::cat fepC double mutants were also small but of normal color on LB and LB* plates. The pink coloration thus seems to require entry of the Ent-Fe ${ }^{3+}$ complex into the cytoplasm; this may reflect oxidation of periplasmic enterochelin in the fep mutants by CueO (Grass et al., 2004). The phenotypes of fepB and fepC strains, like those of the fes::cat mutant, were suppressed by $\mathrm{FeCl}_{3}$ (but not by other metal ions) and by ascorbate and citrate, the latter two being more effective in rich media.

The entB single mutant, specifically blocked in enterochelin synthesis, formed large colonies nearly identical to those formed by the parental strain on both rich medium and M9 glucose plates, indicating that, in the absence of enterochelin, alternative uptake systems are able to provide enough iron to support normal growth. Interestingly, the entB mutation is epistatic to the fes::cat mutation: the fes::cat entB double mutant formed colonies of almost 
normal size and normal coloration on LB, LB* and M9 glucose plates (Table 1 and data not shown). Similar epistasis was observed on rich medium plates when the entB mutation was replaced by an aroA::Tn10 allele, which blocks enterochelin synthesis upstream of chorismic acid synthesis (data not shown). This suppression is explained below.

All the above genes (except aroA) are repressed by the Fur protein when the iron supply is sufficient and derepressed when iron is limiting. Consistent with this, introduction of a fur mutation into the above strains had little effect on colony size for all strains on all plates (Table 1).

It thus appears that enterochelin, when it is synthesized but cannot be used by the cells, as in the fes and fep mutants, causes slow growth on rich plates and near absence of growth on M9 glucose plates, which have a low iron concentration; this slow growth is not observed in the absence of enterochelin synthesis. The presence of secreted enterochelin around the colonies probably reduces the efficiency of alternative iron uptake systems (see below). In addition, the fes:: cat $\left(\right.$ ent $\left.^{+}\right)$mutant accumulates a substance - most likely cytoplasmic Ent$\mathrm{Fe}^{3+}-$ which confers a pink color on the colonies. Suppression of the fes::cat mutant phenotypes by increasing the iron concentration or activating alternative iron uptake pathways could reflect repression of enterochelin synthesis under these conditions, thereby eliminating its inhibitory effect on the growth of the fes and fep mutants.

Our results can be explained by a double hypothesis: first, that the fes mutation causes iron limitation during growth on rich medium plates, and second, that iron limitation causes SpoT-dependent ppGpp accumulation, resulting in mecillinam resistance. The experiments below were designed to test these ideas.

\section{Iron limitation and increased ppGpp levels in the fes::cat mutant: gene fusion studies}

We first wished to quantify the growth rates of our strains and their levels of expression of the $\mathrm{P} 1_{\text {rrn } B}:: l a c Z$ and $f i u:: l a c Z$ fusions, used to estimate ppGpp levels and iron availability, respectively. Surprisingly, however, when we grew the fes::cat mutant strains in liquid LB or LB*, they all had a generation time of 19-20 minutes, similar to the parental strains CF6301 and DV310, and there was no further improvement of their growth by the addition of citrate, ascorbate or $\mathrm{FeCl}_{3}$ (data not shown; $c f$. below and Discussion). 
Expression of the two lacZ fusions was strongly affected in the fes mutant when grown on LB or LB* plates supplemented with $\mathrm{X}-\mathrm{Gal}$. $\mathrm{P} 1_{r r n B}:$ :lacZ was expressed at a lower level than in the parental strain (pale blue colonies), indicating an increased pool of ppGpp, and fiu::lacZ expression was higher than in the parental strain (dark blue colonies), indicating iron limitation. However, when grown in liquid LB or LB*, the fes mutant strains exhibited the same level of expression as the parental strains for the two fusions (data not shown). Since the fes::cat mutant had a clear growth impairment and was strongly affected in the expression of the two fusions when grown on solid media, we carried out our $\beta$-galactosidase assays on bacteria recovered directly from colonies on plates ( $c f$. Experimental Procedures).

Using these two transcriptional fusions and assaying the $\beta$-galactosidase activity in colonies picked from plates, we quantified the degree of iron limitation and the ppGpp increase in the fes::cat mutant. Expression of the $\mathrm{P} 1_{r r n}::$ lac $Z$ fusion is reduced fourfold on LB plates (Table 2A), indicating a substantially higher ppGpp pool in the fes::cat mutant than in the parental strain. Expression of the fiu::lacZ fusion is increased more than tenfold in the mutant on both LB and LB* plates (Table 2B and data not shown), indicating iron limitation.

Mutants blocked in enterochelin synthesis (entB and fes::cat entB) or in the entry of the Ent-Fe ${ }^{3+}$ complex ( $f e p B, f e p C$, fes::cat fepB and fes::cat fepC) were as strongly derepressed as fes::cat for fiu::lacZ expression on LB and $\mathrm{LB}^{*}$ plates (Table $2 \mathrm{~B}$ and data not shown). Furthermore, this seems to be the maximum level since inactivation of the Fur repressor did not increase it. Thus all mutants lacking a functional enterochelin system are iron limited when growing on LB or LB* plates. Even the entB and fes::cat entB strains, which seem to have a normal growth rate as judged by colony size, are derepressed for the Fur regulon, indicating that the alternative iron uptake systems are barely able to maintain rapid growth on these plates.

The $f e p B$ and $f e p C$ mutants were also repressed for $\mathrm{P} 1_{r r n B}:: l a c Z$ expression, approximately to the same extent as fes::cat (Table 2A), indicating a swollen ppGpp pool during growth on LB plates. Repression of the $\mathrm{P} 1_{r r n B}:$ :lac $Z$ fusion does not depend on the Fur protein because it was also observed in the fur fes::cat, fur fepB and fur fepC double mutants (Table 2A and data not shown). The entB mutant, in contrast, had a near normal level of 
$\mathrm{P} 1_{r r n B}::$ lacZ expression, as did the fes::cat entB double mutant (Table 2A). Thus these latter strains, although iron limited, seem to have a normal ppGpp pool, in keeping with their apparently normal growth rate on LB plates. The swelling of the ppGpp pool thus seems to occur when enterochelin is synthesized and secreted into the solid medium but the Ent-Fe ${ }^{3+}$ complex cannot be utilized by the cells.

We next quantified the effect on the fusions of the addition of citrate, $\mathrm{FeCl}_{3}$ or ascorbate to $\mathrm{LB}$ and $\mathrm{LB}^{*}$ plates. For the $f e s: \mathrm{cat}$, $f e p B$ and $f e p C$ single mutants, these additions restored an almost normal level of expression of the $\mathrm{P} 1_{r r n B}::$ lacZ fusion (Table $2 \mathrm{~A}$ ) and partially (citrate) or totally (ascorbate) suppressed iron limitation as estimated from the expression of the fiu::lacZ fusion (Table 2B).

The observed RelA-independent increase in the ppGpp pools was confirmed to be

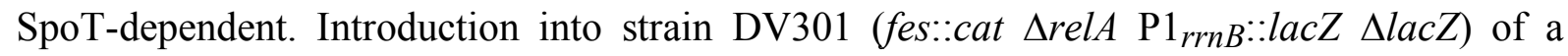
$\Delta s p o T$ deletion, which eliminates ppGpp, increased the colony size and restored high $\mathrm{P} 1_{\text {rrn } B}:$ :lacZ expression (Table $2 \mathrm{~A}$ ). This confirmed that the low level of $\mathrm{P} 1_{\text {rrn } B}:$ :lacZ expression observed in the fes::cat strains was indeed due to an increased ppGpp pool. In contrast, the $\triangle$ spoT mutation did not prevent derepression of fiu::lacZ expression in fes::cat strains (Table 2B).

\section{Iron starvation, ppGpp synthesis and mecillinam resistance}

The fes::cat mutant was originally selected for its mecillinam resistant phenotype on LB plates. Analysis of its overall phenotype led us to hypothesize that it is iron limited and that iron limitation results in SpoT-dependent ppGpp synthesis and hence mecillinam resistance. The data presented above confirm these speculations. In the course of our analysis, we observed that other mutants affected in iron acquisition are also iron limited on LB or LB* plates ( $c f$. Table 2B). We therefore investigated their plating efficiency in the presence of mecillinam.

No single mutant other than fes::cat was mecillinam resistant on LB or LB* plates. Even the $f e p B$ and $f e p C$ mutants were sensitive (Table 3 and data not shown), although our results with the fiu::lacZ and $\mathrm{P} 1_{r r n B}:$ :lacZ fusions indicate that they are iron limited and have a higher ppGpp pool than the parental strain (Table 2). Moreover, the fes::cat fepB and 
fes::cat fepC double mutants had only $1 \%$ plating efficiency in the presence of mecillinam, compared to over $50 \%$ for the fes::cat single mutant, indicating partial suppression of the fes::cat mutation in the absence of uptake of the Ent-Fe ${ }^{3+}$ complex. The entB mutant, which did not show repression of $\mathrm{P} 1_{r r n B}:: l a c Z$ (Table $2 \mathrm{~A}$ ), was also mecillinam sensitive on LB* plates and, in addition, the entB mutation completely suppressed the mecillinam resistance of fes::cat, showing that the synthesis of enterochelin is actually required for this resistance, as it is for the pink coloration of the colonies, slow growth, iron limitation and ppGpp accumulation. Inactivation of the fur gene did not confer mecillinam resistance, indicating that derepression of all genes involved in iron uptake is not in itself sufficient to confer this phenotype. Finally, as expected, the fes::cat mutation failed to confer mecillinam resistance in the absence of ppGpp, i.e., when spoT is deleted (Table 3).

The presence of ascorbate $(10 \mathrm{mM})$ or $\mathrm{FeCl}_{3}(0.1 \mathrm{mM})$ completely abolished the mecillinam resistance of the fes::cat mutant, whereas the addition of $\mathrm{MgSO}_{4}, \mathrm{MnCl}_{2}, \mathrm{ZnSO}_{4}$, $\mathrm{CuSO}_{4}$ or $\mathrm{CoCl}_{2}$ (each $10 \mathrm{mM}$ ) did not (Table 3 and data not shown). The presence of citrate $(10 \mathrm{mM})$ did not suppress the mecillinam resistance of the fes::cat mutant on LB* mecillinam plates, although it decreased the colony size; however, citrate abolished the partial resistance of the fes::cat fepB and fes::cat fepC double mutants (Table 3 and data not shown). We conclude that reestablishment of an adequate iron supply suppresses the mecillinam resistance of the fes::cat mutant and that this is accomplished efficiently by adding ascorbate or iron to the medium but only partially by adding citrate.

\section{Effect of iron chelation}

The presence of chemical chelators can considerably reduce the availability of iron. Addition of the iron chelator dipyridyl $(0.25 \mathrm{mM})$ to plates had several effects. First, it improved the partial mecillinam resistance of the fes::cat mutant in classical LB, although it did not confer resistance on any of the other strains (Tables 3 and 4). Second, when dipyridyl was present in M9 glucose Casaminoacids plates, it prevented all mutants affected in enterochelin metabolism from forming colonies, although the parental strain grew well on this medium (Table 4). Third, unexpectedly, when present in classical LB plates, dipyridyl prevented the growth of the fes::cat ent $B^{ \pm}$mutants completely lacking ppGpp ( $\Delta$ relA $\left.\Delta s p o T\right)$, although all 
the other strains were able to form colonies (Table 4). These two strains were also the only ones unable to grow on M9 glucose Casaminoacids plates in the absence of dipyridyl. Finally, the $f e s^{+}$ppGpp deficient strain, although able to grow in the presence of dipyridyl on both LB and M9 glucose Casaminoacids plates, formed smaller colonies in its presence than its $\Delta r e l A$ spot $T^{+}$parent (Table 4). These observations show that the enterochelin system is required for growth on M9 glucose Casaminoacids dipyridyl plates and provide a clue that ppGpp somehow activates enterochelin synthesis (see below). Overall, these results are also taken to show that SpoT responds to iron limitation, causing ppGpp accumulation by increasing the ratio of (p)ppGpp synthesis to hydrolysis.

\section{Stimulatory effect of ppGpp on iron accumulation systems}

On M9 glucose Casaminoacids plates containing dipyridyl, the enterochelin system is absolutely required for colony formation: the parental strain grows well whereas no growth is observed with all mutants lacking this pathway (fes::cat, fep, entB, fes::cat fep, fes::cat entB; Table 4). On these plates a strain with an intact enterochelin system but lacking ppGpp ( $\triangle$ relA $\Delta$ spoT) is severely handicapped, forming microcolonies visible only after two days' incubation. This suggests that the level of enterochelin expression is considerably lower in the absence of ppGpp than in its presence. We confirmed this hypothesis by the use of CAS plates containing chrome azurol S, glucose and Casaminoacids. On these plates, secreted enterochelin forms a halo surrounding the colonies, the diameter of which is a measure of the quantity secreted. As seen in Fig. 1, in the absence of ppGpp the halo is much smaller than in its presence, in both $\mathrm{fur}^{+}$and fur strains, confirming the predicted positive effect of ppGpp on enterochelin production and further showing that this regulation is Fur-independent.

Our data also suggest a stimulatory role of ppGpp on the expression of one or more alternative (non-enterochelin) iron uptake systems. This is seen by the growth patterns on M9 glucose Casaminoacids without dipyridyl and on LB plates containing dipyridyl. On these plates the enterochelin system is not required, as evidenced by growth of the fes::cat, fep and entB mutants (Table 4); the alternative systems work efficiently. In the absence of ppGpp, however, the fes::cat ( $\triangle$ relA $\Delta$ spoT) and fes::cat entB ( $\triangle$ relA $\Delta$ spoT) strains are no longer able 
to form colonies (Table 4), strongly suggesting lower expression of one or more alternative systems of iron acquisition in the absence of ppGpp.

\section{Assays of ppGpp in liquid culture}

We next wished to quantify the SpoT-dependent increase in the ppGpp pool during iron limitation. Unlike the $\beta$-galactosidase assay, our ppGpp assay, involving ${ }^{32} \mathrm{P}$, cannot be carried out on bacteria recovered from colonies. We therefore looked for conditions causing iron limitation in liquid medium, first exploiting the iron chelator dipyridyl. In MOPS medium supplemented with glucose, all 20 amino acids and $\mathrm{FeS}_{4}(1 \mu \mathrm{M})$, the presence of $0.25 \mathrm{mM}$ dipyridyl did not affect the growth of the $\Delta$ relA parental strains. However, the growth of the fes::cat, fep and entB mutants was inhibited about 60 minutes after the addition of the chelator. Under these conditions there was rapid induction of the fiu::lacZ fusion, showing iron starvation, and slower repression of the $\mathrm{P} 1_{\text {rrnB }}:$ lac $Z$ fusion, indicative of an increase in the ppGpp pool (data not shown); since this repression was observed in the entB mutant, it cannot be due to the accumulation of unusable Ent-Fe ${ }^{3+}$ complexes; we presume it is a direct result of iron limitation.

Using strain DV301 (fes::cat $\Delta$ relA ), we assayed the ppGpp pool at different times after the addition of dipyridyl. In our medium containing $0.3 \mathrm{mM}$ phosphate, iron was limiting instead of phosphate when added at concentrations lower than $0.5 \mu \mathrm{M}$. In exponential phase in the presence of excess $\mathrm{FeSO}_{4}(1 \mu \mathrm{M})$, the generation time of the strain was $45 \mathrm{~min}$, the ppGpp concentration was $4 \mathrm{pmol} \mathrm{ml}^{-1} \mathrm{OD}^{-1}$ and the $\mathrm{ppGpp} /(\mathrm{ppGpp}+\mathrm{GTP})$ ratio was less than 0.005 ; the ratio remained at this low level until phosphate became limiting in the medium (Fig. 2). After addition of the chelator, as growth slowed down we observed a slow but regular increase of the ppGpp pool (Fig. 2). Five hours after the addition of dipyridyl, the ppGpp concentration had increased about 10-fold and the ppGpp/(ppGpp + GTP) ratio reached 0.073 (and 0.079 after $6 \mathrm{~h}$ ). These observations show that the fes::cat mutation can indeed cause an increased ppGpp pool, as indicated by the $\mathrm{P} 1_{\text {rrn } B}:$ :lacZ fusion, making it unlikely that the mutant is more sensitive then the parental strain to a given concentration of ppGpp. 
We next followed the evolution of the ppGpp pool during iron depletion without the addition of a chelator, simply by growing the strain in a medium to which no iron had been added. We again observed a continuous increase of the ppGpp pool as the iron was depleted and growth slowed down (Fig. 3A). The addition at this point of $5 \times 10^{-5} \mathrm{M} \mathrm{FeSO}_{4}$ led to a rapid drop of the ppGpp pool to barely detectable levels, with the ppGpp/(ppGpp + GTP) ratio falling from about 0.040 to less than 0.005 . This drop took less than $30 \mathrm{~min}$ and was complete even before growth had resumed.

When the cells were incubated overnight in medium without added iron, the $\mathrm{ppGpp} /(\mathrm{ppGpp}+\mathrm{GTP})$ ratio was even higher, about 0.100 (Fig. 3B). Under these conditions of prolonged starvation, the culture never regained its maximal growth rate after iron readdition. The addition of iron nevertheless led to a rapid drop in the ratio, reaching 0.025 in less than 30 min (Fig. 3B).

These results show conclusively that during iron limitation, there is a RelA-independent SpoT-dependent accumulation of ppGpp in E. coli. 


\section{Discussion}

The level of the regulatory nucleotide ppGpp is elevated during many different physiological stresses. During amino acid starvation the RelA protein is the principal synthetase but during carbon starvation and most other stresses leading to ppGpp accumulation, the SpoT protein is responsible for the increase. The opposing activities of this bifunctional enzyme apparently are coordinately regulated by substrate induced conformational antagonism (Hogg et al., 2004; Mechold et al., 2002), but it is not known how stress mediates changes in the ratio of the synthetase to hydrolase activities of SpoT to bring about ppGpp accumulation. Our previous work established that an expanded ppGpp pool in E. coli allows it to grow and divide in rich medium in the absence of a functional PBP2, whether the inactivation is by mutation or by the highly specific $\beta$-lactam mecillinam. We therefore thought that, starting with a $\Delta$ relA strain, a selection for mecillinam resistant derivatives might produce mutants affected in a putative regulator of SpoT activity, causing a higher ppGpp pool.

In the present work we describe a mecillinam resistant mutant carrying a fes::cat mutation, inactivating enterochelin esterase. The characterization of this strain showed that it is iron limited when growing on rich medium plates, and under these conditions its ppGpp pool is high and SpoT-dependent. This led us to hypothesize that iron starvation leads to SpoT-dependent ppGpp accumulation. We confirmed our hypothesis by direct ppGpp measurements on cultures during iron starvation, caused either by the presence of the iron chelator dipyridyl or through iron depletion by the bacteria.

The Fur protein is the general repressor of genes involved in iron metabolism; repression is relieved when the corepressor $\mathrm{Fe}^{2+}$ is scarce. However, Fur is not involved in the detection of iron limitation by SpoT, since the fes::cat mutation causes the same ppGpp increase independently of the presence or absence of the Fur protein, as judged by the level of expression of the $\mathrm{P} 1_{r r n B}:: l a c Z$ fusion. Conversely, a fur mutant, with high expression of all iron related genes even in the presence of excess iron, has an essentially normal ppGpp pool as judged by the same fusion (Table 2). Thus the SpoT protein must detect iron limitation through some as yet undefined element, possibly the internal concentration of $\mathrm{Fe}^{2+}$ or $\mathrm{Fe}^{3+}$. 
All mutants affected in the enterochelin pathway are iron limited on LB plates, whether the block is in biosynthesis (entB), uptake of the Ent-Fe ${ }^{3+}$ complex $(f e p B, f e p C)$, or release of the iron in the cytoplasm (fes::cat); in all cases, the fiu::lacZ fusion was completely derepressed (Table 2). However, the severity of the iron limitation does not seem to be the same for the different mutants, as judged by colony size on LB plates; according to this criterion, the fes::cat mutant is more strongly limited than the fep mutant, which is more limited than the entB mutant. The discrepancy between colony size and fusion expression is presumably because the fiu::lacZ fusion is simply too sensitive, being fully induced even during mild iron limitation.

It is striking that iron limitation is observed only on plates, not in LB or M9 glucose Casaminoacids liquid culture. A likely explanation for this apparent paradox has to do with the fate of the secreted enterochelin, which traps iron in the medium. If the enterochelin remains near the bacteria that produced it, as would be the case on plates, this would deplete iron locally; the cell's alternative pathways of iron acquisition cannot compete with enterochelin, so that mutants like fes and fep, unable to recover iron from the Ent-Fe ${ }^{3+}$ complexes, would be iron limited. Furthermore, the resulting iron limitation would aggravate the situation further since it would stimulate the cells to produce even more enterochelin; indeed, fes and fep mutants have been shown to secrete large quantities of enterochelin (Langman et al., 1972). In liquid LB culture, in contrast, the secreted enterochelin is dispersed throughout the culture and does not reach a concentration sufficient to titrate out all iron in the medium, so iron is not limiting. In entB mutants, of course, there can be no local depletion on plates since no enterochelin is made; the large colony size of entB strains shows that alternative iron uptake pathways readily provide sufficient iron if it is not trapped by secreted enterochelin. Thus the entB mutation relieves the severe iron limitation caused (on plates) by the fes::cat mutation, allowing faster growth, abolishing the increase in the ppGpp pool and suppressing mecillinam resistance.

The $f e p B$ and $f e p C$ strains, like the fes::cat mutant, are iron limited on LB plates (small colonies, high fiu::lacZ expression) and have a high ppGpp pool (low $\mathrm{P} 1_{r r n B}:$ :lacZ expression) (Table 2), yet they are not mecillinam resistant (Table 4). We do not have an 
explanation for this observation. It is conceivable that mecillinam resistance is somehow favoured by the presence of unhydrolyzed Ent-Fe ${ }^{3+}$ complexes in the cytoplasm, or discouraged by their presence in the periplasm. Alternatively, it is possible that CueOdependent oxidation of the enterochelin moiety of Ent-Fe $3^{+}$complexes in the periplasm releases a small amount of ferric ions that the cells can use. Any of these hypotheses would explain the partial epistasis of the $f e p B$ mutation over fes::cat (cf. Table 3).

SpoT-dependent ppGpp accumulation has been observed after many different stresses (Cashel et al., 1996), but in no case do we know the nature of the signal to which SpoT responds. One speculative scenario draws on the suggestion that SpoT activity responds to the level of uncharged tRNA in the cell (Murray and Bremer, 1996). It is known that iron starvation leads to undermodification of several tRNAs (Björk, 1996); if this results in a lower charge ratio for some species, it might generate a signal that increases the synthesis to hydrolysis ratio of SpoT. Alternatively, one could imagine that iron limitation reduces cytochrome production, thereby reducing respiration and ATP generation and possibly triggering SpoT-dependent ppGpp accumulation, as during carbon starvation.

Our data show that ppGpp stimulates the expression of the enterochelin system and strongly suggest that it stimulates the expression of at least one alternative (non-enterochelin) iron uptake system. Although we have not identified specific targets responsible for this stimulation, it is interesting to note that expression of the fiu::lac $Z$ fusion, completely derepressed in the fes::cat $\Delta$ relA and fur $\Delta$ relA mutants (360 and 370 units, respectively; Table 2B), is significantly reduced in the absence of ppGpp (190 and 240 units; Table 2B). This indicates a positive, Fur-independent effect of ppGpp on the Fur-regulated fiu promoter.

These observations imply the existence of a homeostatic negative feedback loop governing iron acquisition: iron limitation stimulates SpoT-dependent ppGpp accumulation, ppGpp stimulates the synthesis of iron uptake systems, and these in turn help relieve the iron limitation.

The role of iron in bacterial pathogenicity is well documented (see (Ratledge and Dover, 2000) for review). In certain cases, iron-acquisition systems have been shown to be important for virulence whereas, in other cases, iron starvation increases the expression of virulence 
determinants and toxins. The nucleotide ppGpp has also been shown to be involved in virulence. Salmonella strains devoid of ppGpp have been shown to be defective in expression of a number of virulence genes (Pizarro-Cerda and Tedin, 2004), and the gene hilA, coding for the central virulence regulator, absolutely requires ppGpp in order to be expressed, both on entry into stationary phase and during carbon starvation (Song et al., 2004). It will be interesting to determine whether ppGpp is involved in the regulation of siderophore synthesis in pathogenic bacteria and whether it is required for the increased expression of virulence genes caused by iron starvation. It is interesting to note that Merrell et al. (Merrell et al., 2003), studying the effect of iron starvation in the pathogen Helicobacter pylori, observed that it caused the repression of the synthesis of ribosomal proteins and the derepression of genes involved in aminoacid biosynthesis. H. pylori does not accumulate ppGpp in response to aminoacid starvation (Scoarughi et al., 1999), but Merrell et al's results strongly suggest that ppGpp accumulates in response to iron limitation, just as in E. coli. 


\section{Experimental procedures}

\section{Bacterial strains and phages}

All the strains used in this work are E. coli K-12 derivatives; some are described in Table 5. The entB::kan (Staab and Earhart, 1990), the fiu::lacZ fusion (Hantke, 1987) and the $\triangle$ nagEBACD::Tc $\mathrm{R}^{\mathrm{R}}$ allele (Plumbridge, 1992) were kindly provided by C. Earhart, D. Touati and J. Plumbridge, respectively. Strains AN311 (Young and Gibson, 1979) and AN260 (Pierce and Earhart, 1986), kindly provided by K. Hantke, were the donors of the fepB and fepC mutations, respectively.

The $\mathrm{P} 1_{r r n B}:$ :lacZ fusion is integrated within the malEFK operon and has an associated kanamycin resistance (Hernandez and Bremer, 1990). Low values of $\beta$-galactosidase activity are typical for this fusion, which was constructed with a low efficiency ribosome binding site derived from phage $\phi X 174$ (Hernandez and Bremer, 1990).

Strain DV310 (ArelA fiu::lacZ $\Delta$ lacZ) was constructed in a similar way to CF6301 ( $\Delta$ relA $\mathrm{P} 1_{r r n B}:: l a c Z \Delta l a c Z$ ) (Vinella et al., 2000): the $\mathrm{P}_{f i u}:$ :lacZ fusion was generated by insertion of a $\lambda$ placMu53 Km ${ }^{\mathrm{R}}$ in the fiu gene (Hantke, 1987) and transduced by selecting its associated kanamycin resistance. To introduce the $f e p B$ and $f e p C$ mutations into our strains, we first transduced the linked insertion zbe-601::Tn10 into AN311 and AN260; small TcR clones were used as donors to transduce strain CF1742 (relA1) to tetracycline resistance; $\mathrm{Tc}^{\mathrm{R}}$ transductants were screened for inability to grow on minimal glucose plates unless $10^{-2} \mathrm{M}$ citrate was added; these were used, in turn, as donors of the $f e p B$ and fepC mutations by cotransduction with zbe-601::Tn10. This marker was also used to introduce the entB::kan allele into $\mathrm{Km}^{\mathrm{R}}$ backgrounds, selecting $\mathrm{Tc}^{\mathrm{R}}$ transductants that were unable to grow on $\mathrm{M} 9$ glucose plates in the presence of $0.25 \mathrm{mM}$ dipyridyl. To construct the fes::cat fepB and fes::cat fepC derivatives of CF1742, we transduced strains fepB zbe-601::Tn10 and fepC zbe601::Tn10 using a P1 stock grown on a fes::cat entB::kan strain and selecting for chloramphenicol resistance; $\mathrm{Cm}^{\mathrm{R}} \mathrm{Km}^{\mathrm{S}}$ transductants were of two types: clones forming pink colonies (presumed to be fes::cat single mutants) and clones forming colonies of normal coloration (presumed to be fes::cat fep double mutants). To confirm the genotype of the 
strains, P1 stocks were grown on the two types of transductants and used to transduce strain CF1742 to chloramphenicol resistance; P1 grown on the presumed fes::cat single mutant gave only pink $\mathrm{Cm}^{\mathrm{R}}$ transductants while $\mathrm{P} 1$ grown on the presumed fes::cat fep double mutant gave both pink and normal transductants in a ratio consistent with the genetic map (gene order fes..fepC...fepB...entB). The fes::cat entB::kan derivatives of CF6301 and DV310 were made by transducing these parental strains (which are $\mathrm{Km}^{\mathrm{R}}$ ) with a $\mathrm{P} 1$ stock grown on a fes::cat entB::kan donor strain and selecting $\mathrm{Cm}^{\mathrm{R}}$ transductants on $\mathrm{LB}$ plates; we obtained small $\mathrm{Cm}^{\mathrm{R}}$ pink colonies (fes::cat single mutants) and bigger clones of normal coloration (fes::cat entB::kan double mutants). These genotypes were confirmed by the respective inability or ability of P1 stocks grown on the transductants to cotransduce kanamycin resistance with chloramphenicol resistance.

The fur::kan mutation was introduced into strains CF6301 and DV310 (which are kanamycin resistant) by first introducing a $\triangle n a g E B A C D:: \mathrm{Tc}^{\mathrm{R}}$ allele, then transducing to $\mathrm{Nag}^{+}$ on minimal medium containing $0.2 \% \mathrm{~N}$-acetylglucosamine as carbon source, using a fur::kan donor; cotransduction of the fur::kan mutation was confirmed by the ability to retransfer kanamycin resistance by cotransduction with $\mathrm{nag}^{+}$.

The $\Delta$ spoT207::cat mutation was introduced into $\mathrm{Cm}^{\mathrm{R}}$ recipients by cotransduction with the $z i b-563:: \operatorname{Tn} 10\left(\mathrm{Tc}^{\mathrm{R}}\right)$ marker; spoT cotransductants were detected by their inability to grow on minimal glucose plates containing $10^{-2} \mathrm{M}$ citrate. This allele was from strain CF1693.

\section{Media and growth conditions}

All bacteria used in this work were grown at $37^{\circ} \mathrm{C}$. Our mecillinam resistant mutants were originally selected on classical LB plates (Miller, 1992) in one laboratory but, for an unknown reason, this phenotype was not reproducible in a second laboratory unless $1 \% \mathrm{KCl}$ was added to standard LB (called LB* medium); we therefore included experiments on LB* medium in our subsequent analysis. Minimal medium was M9 (Miller, 1992); glucose (0.4\%), Casaminoacids $(0.4 \%)$ or aminoacids $(0.01 \%)$ were added as noted. For ppGpp assays, MOPS (Neidhardt et al., 1974) was used, supplemented with $0.2 \%$ glucose, $0.3 \mathrm{mM}$ phosphate and all 20 amino acids (40 $\mu \mathrm{g} \mathrm{ml}^{-1}$ each); the concentration of iron and additional supplements are specified in the text. Estimates of enterochelin secretion were made on 
chrome azurol S (CAS) plates (Schwyn and Neilands, 1987) supplemented with $0.4 \%$ glucose and $0.3 \%$ Casaminoacids. Solid media contained 1.5\% agar. Antibiotics were used at the following concentrations: chloramphenicol (Cm) $20 \mu \mathrm{g} \mathrm{ml}^{-1}$; kanamycin $(\mathrm{Km}) 40 \mu \mathrm{g} \mathrm{ml}^{-1}$; mecillinam (Mec) $10 \mu \mathrm{g} \mathrm{ml}^{-1}$; tetracycline (Tc) $20 \mu \mathrm{g} \mathrm{ml}^{-1}$; ampicillin (Amp) $100 \mu \mathrm{g} \mathrm{ml}^{-1}$. XGal (5-bromo-4-chloro-3-indolyl- $\beta$-D-galactoside) was added at $40 \mu \mathrm{g} \mathrm{ml}^{-1}$ when indicated. All cultures and plates were incubated at $37^{\circ} \mathrm{C}$. X-Gal and 2, $2^{\prime}$-dipyridyl were from Sigma Chemical Co.

\section{Test for mecillinam resistance}

The susceptibility of strains to mecillinam was tested by plating on LB or LB* plates supplemented with $10 \mu \mathrm{g} \mathrm{ml}^{-1}$ mecillinam, a generous gift of Laboratoires Léo (France); for plasmid-bearing strains, antibiotics required for plasmid maintenance were also added; additional supplements are indicated in the text. Plates were incubated three nights. Cultures were plated in parallel on identical plates lacking mecillinam and the ratio of the two titers was calculated. When this efficiency of plating was greater than 0.3 the strain was considered resistant, when less than $3 \times 10^{-4}$, sensitive.

\section{$\beta$-galactosidase assays}

Tests on liquid cultures were carried out as described (Miller, 1992). For assays on colonies, we prepared plates with about 50 colonies, then picked colonies into $1.5 \mathrm{ml}$ of $\mathrm{Z}$ buffer, using several colonies if necessary to reach a final $\mathrm{OD}_{600}$ of 0.1 to $0.2 ; 1 \mathrm{ml}$ was used for $\beta$ galactosidase assays. For both fusions used in this work, the ratio of $\beta$-galactosidase activity in the parental strain to that in the fes mutant changes with the incubation time of the plates but remains approximately constant between 20 and 30 hours (Fig. 4). All measurements presented here were made after 24 to $26 \mathrm{~h}$ incubation of the plates. Numbers shown in the tables are mean values obtained from at least 10 measurements; in all cases, the observed deviation did not exceed $10 \%$.

\section{Estimates of enterochelin secretion}

Overnight LB cultures were centrifuged and washed twice in $10^{-2} \mathrm{M} \mathrm{MgSO}_{4} ; 1 \mu \mathrm{l}$ of each suspension was deposed on a CAS plate, which was then incubated for 48 hours. 
ppGpp assay

The ppGpp concentration was measured in cells grown in MOPS glucose minimal medium with $40 \mu \mathrm{g} \mathrm{ml}^{-1}$ (each) of all 20 amino acids and containing ${ }^{32} \mathrm{P}\left(0.1 \mathrm{mCi} / 0.4 \mu \mathrm{mol} \mathrm{ml}^{-1}\right)$ and various concentrations of $\mathrm{FeSO}_{4}$. Nucleotides were extracted by adding ice cold formic acid to 6.5 M. Samples were frozen and thawed at least twice before being spotted on PEI plates (Polygram CEL 300, Macherey-Nagel). One-dimensional chromatography was carried out in 1.5 $\mathrm{M} \mathrm{KH}_{2} \mathrm{PO}_{4}$. Quantification was with a Storm PhosphorImager.

\section{DNA techniques and plasmids}

Plasmids were extracted and transformation was carried out as described by Sambrook et al. (Sambrook et al., 1989). The cloning vectors used in this work were pKS+ (high copy Amp ${ }^{\mathrm{R}}$, Stratagene) and pBAD18 (high copy $\mathrm{Km}^{\mathrm{R}}$ (Guzman et al., 1995)). All clonings were carried out in strain XL1 Blue (Stratagene).

To localize the mini- $\operatorname{Tn} 10\left(\mathrm{Cm}^{\mathrm{R}}\right)$ element present in the mcr-14::cat mutant, chromosomal DNA was extracted from strain DV53 (CF6301 mcr-14::cat) and digested with $B s t \mathrm{UI}$, a restriction enzyme that does not cut in the inserted sequence. From this digest we cloned the cat gene in the vector pKS+ linearized with SmaI. To sequence the chromosomal DNA adjacent to the ends of the mini-Tn10 insertion element, we used synthetic primers ( $5^{\prime}$ to $\left.3^{\prime}\right) \mathrm{CmD}=$ TTATTCTGCCTCCCAGAGCC and $\mathrm{CmF}=$ AACGGCAAAAGCACCGCCGG. PCR amplification of the $\mathrm{fes}^{+}$gene and promoter was carried out with Taq polymerase (Perkin Elmer) using the primers $\left(5^{\prime}\right.$ to $\left.3^{\prime}\right)$ FesUP = AAGAATTCCCATTACGCTATTGCAAAT-GCAAAT and FesDO = AAACTGCAGATTACTGAATGCCATATTCAACTCC. The $1.25 \mathrm{~kb}$ amplified fragment was digested by EcoRI and PstI, then cloned into pBAD18, generating pDV51, whence it was subcloned into $\mathrm{pKS}+$, generating pDV52. 


\section{References}

Aono, R., Yamasaki, M., and Tamura, G. (1979) High and selective resistance to mecillinam in adenylate cyclase-deficient or cyclic adenosine 3',5'-monophosphate receptor proteindeficient mutants of Escherichia coli. J Bacteriol 137: 839-845.

Artsimovitch, I., Patlan, V., Sekine, S.-I., Vassylyeva, M.N., Hosaka, T., Ochi, K., and Vassylyev, D. (2004) Structural basis for transcription regulation by alarmone ppGpp. Cell 117: 299-310.

Bachmann, B.J. (1996) Derivations and genotypes of some mutant derivatives of Escherichia coli K-12. In Escherichia coli and Salmonella: Cellular and Molecular Biology. Neidhardt, F.C., Ingraham, J.L., Low, K.B., Magasanik, B., Schaechter, M., and Umbarger, H.E. (eds). Washington, D. C.: American Society for Microbiology, pp. 2460-2488.

Björk, G.R. (1996) Stable RNA modification. In Escherichia coli and Salmonella: Cellular and Molecular Biology. Neidhardt, F.C., Ingraham, J.L., Low, K.B., Magasanik, B., Schaechter, M., and Umbarger, H.E. (eds). Washington, D. C.: American Society for Microbiology, pp. 861-886.

Bullock, W.O., Fernandez, J.M., and Short, J.M. (1987) XL1-Blue: A high efficiency plasmid transforming recA Escherichia coli strain with beta-galactosidase selection. BioTechniques 5: $376-378$.

Cashel, M., Gentry, D.R., Hernandez, V.J., and Vinella, D. (1996) The stringent response. In Escherichia coli and Salmonella: Cellular and Molecular Biology. Neidhardt, F.C., Ingraham, J.L., Low, K.B., Magasanik, B., Schaechter, M., and Umbarger, H.E. (eds). Washington, D. C.: American Society for Microbiology, pp. 1458-1496.

Earhart, C.F. (1996) Uptake and metabolism of iron and molybdenum. In Escherichia coli and Salmonella: Cellular and Molecular Biology. Neidhardt, F.C., Ingraham, J.L., Low, K.B., Magasanik, B., Schaechter, M., and Umbarger, H.E. (eds). Washington, D. C.: American Society for Microbiology, pp. 1075-1090.

Geissmann, T.A., and Touati, D. (2004) Hfa, a new chaperoning role: binding to messenger RNA determines access for small RNA regulator. EMBO J 23: 396-405. 
Grass, G., Thakali, K., Klebba, P.E., Thieme, D., Muller, A., Wildner, G.F., and Rensing, C. (2004) Linkage between catecholate siderophores and the multicopper oxidase $\mathrm{CueO}$ in Escherichia coli. J Bacteriol 186: 5826-5833.

Guzman, L.-M., Belin, D., Carson, M.J., and Beckwith, J. (1995) Tight regulation, modulation, and high-level expression by vectors containing the arabinose $\mathrm{P}_{\mathrm{BAD}}$ promoter. J Bacteriol 177: 4121-4130.

Hantke, K. (1987) Selection procedure for deregulated iron transport mutants (fur) in Escherichia coli K 12: fur not only affects iron metabolism. Mol Gen Genet 210: 135-139.

Hernandez, V.J., and Bremer, H. (1990) Guanosine tetraphosphate (ppGpp) dependence of the growth rate control of $r r n B$ P1 promoter activity in Escherichia coli. J Biol Chem 265: 11605-11614.

Hogg, T., Mechold, U., Malke, H., Cashel, M., and Hilgenfeld, R. (2004) Conformational antagonism between opposing active sites in a bifunctional RelA/SpoT homolog modulates (p)ppGpp metabolism during the stringent response. Cell 117: 57-68.

Joseleau-Petit, D., Thévenet, D., and D'Ari, R. (1994) ppGpp concentration, growth without PBP2 activity and growth rate control in Escherichia coli. Mol Microbiol 13: 911-917.

Langman, L., Young, I.G., Frost, G.E., Rosenberg, H., and Gibson, F. (1972) Enterochelin system of iron transport in Escherichia coli: mutations affecting ferric-enterochelin esterase. J Bacteriol 112: 1142-1149.

Lund, F., and Tybring, L. (1972) 6 6 -amidinopenicillanic acid - a new group of antibiotics. Nature New Biol 236: 135-137.

Masse, E., Escorcia, F.E., and Gottesman, S. (2002) Coupled degradation of a small regulatory RNA and its mRNA targets in Escherichia coli. Genes \& Dev 17: 2374-2383.

Masse, E., and Gottesman, S. (2002) A small RNA regulates the expression of genes involved in iron metabolism in Escherichia coli. Proc Natl Acad Sci USA 99: 4620-4625.

Mechold, U., Murphy, H., Brown, L., and Cashel, M. (2002) Intramolecular Regulation of the opposing (p)ppGpp catalytic activities of $\mathrm{Rel}_{S e q}$, the Rel/Spo enzyme from Streptococcus equisimilis. J Bacteriol 184: 2878-2888. 
Merrell, D.S., Thompson, L.J., Kim, C.C., Mitchell, H., Tompkins, L.S., Lee, A., and Falkow, S. (2003) Growth phase-dependent response of Helicobacter pylori to iron starvation. Infection and Immunity 71: 6510-6525.

Miller, J.H. (1992) A Short Course in Bacterial Genetics. Cold Spring Harbor, N. Y.: Cold Spring Harbor Laboratory Press.

Murray, K.D., and Bremer, H. (1996) Control of spoT-dependent ppGpp synthesis and degradation in Escherichia coli. J Mol Biol 259: 41-57.

Neidhardt, F.C., Bloch, P.L., and Smith, D.F. (1974) Culture medium for enterobacteria. $J$ Bacteriol 119: 736-747.

Paul, B.J., Barker, M.M., Ross, W., Schneider, D.A., Webb, C., Foster, J.W., and Gourse, R. (2004) DksA: a critical component of the transcription initiation machinery that potentiates the regulation of rRNA promoters by ppGpp and the initiating NTP. Cell 118: 311-322.

Perederina, A., Svetlov, V., Vassylyeva, M.N., Tahirov, T.H., Yokoyama, S., Artsimovitch, I., and Vassylyev, D.G. (2004) Regulation through the secondary channel-structural framework for ppGpp-DksA synergism during transcription. Cell 118: 297-309.

Pierce, J.R., and Earhart, C.F. (1986) Escherichia coli K-12 envelope proteins specifically required for ferrienterobactin uptake. J Bacteriol 166: 930-936.

Pizarro-Cerda, J., and Tedin, K. (2004) The bacterial signal molecule, ppGpp, regulates Salmonella virulence gene expression. Mol Microbiol 52: 1827-1844.

Plumbridge, J.A. (1992) A dominant mutation in the gene for the Nag repressor of Escherichia coli that renders the nag regulon uninducible. $J$ Gen Microbiol 138: 10111017.

Ratledge, C., and Dover, L.G. (2000) Iron metabolism in pathogenic bacteria. Annu Rev Microbiol 54: 881-941.

Sambrook, J., Fritsch, E.F., and Maniatis, T. (1989) Molecular cloning: a laboratory manual. Cold Spring Harbor, N. Y.: Cold Spring Harbor Laboratory.

Schwyn, B., and Neilands, J.B. (1987) Universal chemical assay for the detection and determination of siderophores. Anal Biochem 160: 47-56. 
Scoarughi, G.L., Cimmino, C., and Donini, P. (1999) Helicobacter pylori: a eubacterium lacking the stringent response. J Bacteriol 181: 552-555.

Seyfzadeh, M., Keener, J., and Nomura, M. (1993) SpoT-dependent accumulation of guanosine tetraphosphate in response to fatty acid starvation in Escherichia coli. Proc Natl Acad Sci USA 90: 11004-11008.

Song, M., Kim, H.J., Kim, E.Y., Shin, M., Lee, H.C., Hong, Y., Rhee, J.H., Yoon, H., Ryu, S., Lim, S., and Choy, H.E. (2004) ppGpp-dependent stationary phase induction of genes on Salmonella pathogenicity island 1. J Biol Chem 279: 34183-34190.

Spira, B., Silberstein, N., and Yagil, E. (1995) Guanosine 3',5'-bispyrophosphate (ppGpp) synthesis in cells of Escherichia coli starved for $\mathrm{P}_{\mathrm{i}} . J$ Bacteriol 177: 4053-4058.

Spratt, B.G. (1975) Distinct penicillin binding proteins involved in the division, elongation, and shape of Escherichia coli K-12. Proc Natl Acad Sci USA 72: 2999-3003.

Spratt, B.G. (1977) The mechanism of action of mecillinam. J Antimicrob Chemother 3(supp B): $13-19$.

Spratt, B.G., and Pardee, A.B. (1975) Penicillin-binding protein and cell shape in E. coli. Nature 254: 515-517.

Staab, J.F., and Earhart, C.F. (1990) EntG activity of Escherichia coli enterobactin synthetase. J Bacteriol 172: 6403-6410.

Stent, G.S., and Brenner, S. (1961) A genetic locus for the regulation of ribonucleic acid biosynthesis. Proc Natl Acad Sci USA 47: 2005-2014.

Villadsen, I.S., and Michelsen, O. (1977) Regulation of PRPP and nucleoside tri and tetraphosphate pools in Escherichia coli under conditions of nitrogen starvation. $J$ Bacteriol 130: 136-143.

Vinella, D., Cashel, M., and D'Ari, R. (2000) Selected amplification of the cell division genes ftsQ-ftsA-ftsZ in Escherichia coli. Genetics 156: 1483-1492.

Vinella, D., D’Ari, R., Jaffé, A., and Bouloc, P. (1992) Penicillin-binding protein 2 is dispensable in Escherichia coli when ppGpp synthesis is induced. EMBO J 11: 1493-1501. 
Vinella, D., Joseleau-Petit, D., Thévenet, D., Bouloc, P., and D'Ari, R. (1993) Penicillinbinding protein 2 inactivation in Escherichia coli results in cell division inhibition, which is relieved by FtsZ overexpression. J Bacteriol 175: 6704-6710.

Wendrich, T., Glaha, G., Wilson, D.N., Marahiel, M.A., and Nierhaus, K.H. (2002) Dissection of the mechanism for the stringent factor RelA. Cell 10: 779-788.

Xiao, H., Kalman, M., Ikehara, K., Zemel, S., Glaser, G., and Cashel, M. (1991) Residual guanosine 3',5'-bispyrophosphate synthetic activity of relA null mutants can be eliminated by spoT null mutations. J Biol Chem 266: 5980-5990.

Young, I.G., and Gibson, F. (1979) Isolation of enterochelin from Escherichia coli. Methods Enzymol 56: 394-398. 
Table 1. Growth on plates

Strain

Growth $^{a}$ on plates of

\begin{tabular}{|c|c|c|c|c|}
\hline & M9 glucose & LB & $\mathrm{LB}+\mathrm{Cit} b$ & $\mathrm{LB}+\mathrm{Asc}^{b}$ \\
\hline Parental $^{c}$ & ++ & ++ & ++ & ++ \\
\hline fes::cat (mcr-14::cat) & \pm & $+(\mathrm{p})$ & $++(p)$ & ++ \\
\hline$f e p B^{c}$ & \pm & + & ++ & ++ \\
\hline entB & ++ & ++ & ++ & ++ \\
\hline fes::cat fep $B^{d}$ & \pm & + & ++ & ++ \\
\hline fes::cat entB & ++ & ++ & ++ & ++ \\
\hline fur & ++ & ++ & ++ & ++ \\
\hline furfes::cat & \pm & $+(\mathrm{p})$ & $++(p)$ & ++ \\
\hline fur fep $B^{d}$ & \pm & + & ++ & ++ \\
\hline fur entB & ++ & ++ & ++ & ++ \\
\hline
\end{tabular}

${ }^{a}$ The strains were cultivated overnight in liquid LB and washed twice with M9 medium before

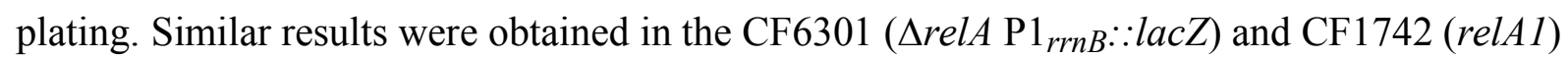
strain backgrounds. "++" indicates normal colony size and "+" indicates small colonies after overnight incubation (LB plates) or two nights” incubation (M9 glucose plates); “ $\pm ”$ represents microcolonies visible only after three days; "p" indicates pink coloration of the colonies.

b"Cit" is $10 \mathrm{mM}$ citrate, "Asc" is $10 \mathrm{mM}$ ascorbate; addition of $0.1 \mathrm{mM} \mathrm{FeCl}_{3}$ gave the same results as ascorbate.

${ }^{c}$ The parental strain was CF6301 ( $\Delta$ relA).

$d$ The same results were obtained when the strain carried a fepC mutation instead of fep $B$. 
Table 2. Expression of the $P 1_{r r n B}:: l a c Z$ and fiu::lacZ fusions

in mutants affected in enterochelin-dependent iron uptake

\begin{tabular}{|c|c|c|c|}
\hline \multicolumn{4}{|c|}{ A. Expression of the $P 1_{r r n B}:$ :lac $Z$ fusion in $\Delta r e l A$ strains $a$} \\
\hline Strain & LB & $\mathrm{LB}+\mathrm{Cit}^{b}$ & $\mathrm{LB}+\mathrm{Asc}^{b}$ \\
\hline Parental $c$ & 17 & 15 & 14 \\
\hline fes::cat & 4.1 & 10 & 13 \\
\hline fepB & 4.5 & 9 & 15 \\
\hline entB & 12 & 13 & 14 \\
\hline fes::cat fepB & 3.2 & 7.5 & 9.5 \\
\hline fes::cat entB & 12 & 13 & 13 \\
\hline fur & 11 & 9 & 9.5 \\
\hline fur fes::cat & 2.3 & 4.1 & 3.4 \\
\hline fur fepB & 2.1 & 9.6 & 5.5 \\
\hline fur entB & 11 & 8 & 8.2 \\
\hline$\Delta$ spoT & 18 & 16 & 16 \\
\hline$\Delta$ spoT fes::cat & 20 & 17 & 22 \\
\hline$\Delta$ spoT fes::cat ent $B$ & 18 & 19 & 18 \\
\hline$\Delta$ spot fur & 15 & 10 & 15 \\
\hline
\end{tabular}

${ }^{a}$ Assayed on suspensions of colonies picked from LB plates and expressed in Miller units (Miller, 1992).

$b$ "Cit" is $10 \mathrm{mM}$ citrate, "Asc" is $10 \mathrm{mM}$ ascorbate; addition of $0.1 \mathrm{mM} \mathrm{FeCl}_{3}$ gave the same results as ascorbate.

${ }^{c}$ The parental strain was CF6301 ( $\Delta$ relA). 


\section{B. Expression of the fiu: :lacZ fusion in $\Delta r e l A$ strains $a$}

\begin{tabular}{|c|c|c|c|}
\hline Strain & LB & $\mathrm{LB}+\mathrm{Cit}^{b}$ & $\mathrm{LB}+\mathrm{Asc}^{b}$ \\
\hline Parental $^{c}$ & 20 & 17 & $<5$ \\
\hline fes::cat & 360 & 82 & $<5$ \\
\hline$f e p B$ & 320 & 82 & $<5$ \\
\hline entB & 300 & 89 & $<5$ \\
\hline fes::cat fepB & 340 & 87 & $<5$ \\
\hline fes::cat entB & 360 & 81 & $<5$ \\
\hline fur & 370 & 390 & 360 \\
\hline fur fes::cat & 330 & 360 & 360 \\
\hline fur ent & 360 & 350 & 360 \\
\hline fur fep & 320 & 360 & 320 \\
\hline$\Delta s p o T$ & 21 & 17 & $<5$ \\
\hline$\Delta$ spoTfes::cat & 190 & 20 & $<5$ \\
\hline$\Delta$ spoT fes::cat ent $B$ & 140 & 20 & $<5$ \\
\hline$\Delta s p o T$ fur & 240 & 300 & 200 \\
\hline
\end{tabular}

a Assayed on suspensions of colonies picked from LB plates and expressed in Miller units (Miller, 1992).

b"Cit" is $10 \mathrm{mM}$ citrate, "Asc" is $10 \mathrm{mM}$ ascorbate; addition of $0.1 \mathrm{mM} \mathrm{FeCl}_{3}$ gave the same results as ascorbate.

${ }^{c}$ The parental strain was DV310 ( $\Delta$ relA $)$. 
Table 3. Mecillinam susceptibility of enterochelin mutants

Strain

Mecillinam resistance ${ }^{a}$ on

\begin{tabular}{|c|c|c|c|c|c|}
\hline & \multicolumn{3}{|c|}{$\mathrm{LB}^{*}$} & \multicolumn{2}{|c|}{ LB } \\
\hline & - & $+\mathrm{Cit}^{b}$ & $+\mathrm{Asc}^{b}$ & - & $+\operatorname{Dip}^{b}$ \\
\hline Parental $^{c}$ & $\mathrm{~S}$ & $\mathrm{~S}$ & $\mathrm{~S}$ & S & S \\
\hline fes::cat & $\mathrm{R}$ & $\mathrm{R}$ & $\mathrm{S}$ & $\mathrm{S} / \mathrm{R}$ & $\mathrm{R}$ \\
\hline$f e p B$ & $\mathrm{~S}$ & $\mathrm{~S}$ & $\mathrm{~S}$ & $\mathrm{~S}$ & S \\
\hline$e n t B$ & $\mathrm{~S}$ & $\mathrm{~S}$ & $\mathrm{~S}$ & S & S \\
\hline fes::cat fepB & $\mathrm{S} / \mathrm{R}$ & $\mathrm{S}$ & $\mathrm{S}$ & S & S \\
\hline fes::cat entB & $\mathrm{S}$ & $\mathrm{S}$ & $\mathrm{S}$ & $\mathrm{S}$ & S \\
\hline fur & $\mathrm{S}$ & $\mathrm{S}$ & $\mathrm{S}$ & S & S \\
\hline fur fes::cat & $\mathrm{R}$ & $\mathrm{R}$ & $\mathrm{S}$ & $\mathrm{S} / \mathrm{R}$ & $\mathrm{R}$ \\
\hline fur fepB & $\mathrm{S}$ & $\mathrm{S}$ & $\mathrm{S}$ & $\mathrm{S}$ & S \\
\hline fur entB & $\mathrm{S}$ & $\mathrm{S}$ & $\mathrm{S}$ & S & S \\
\hline$\Delta s p o T$ & $\mathrm{~S}$ & $\mathrm{~S}$ & $\mathrm{~S}$ & S & S \\
\hline$\Delta s p o T$ fes::cat & S & $\mathrm{S}$ & $\mathrm{S}$ & S & S \\
\hline
\end{tabular}

a Symbols: "R", plating efficiency $>50 \%$ in the presence of $10 \mu \mathrm{g} \mathrm{ml}^{-1}$ mecillinam; "S", plating efficiency $<0.01 \%$ in the presence of $10 \mu \mathrm{g} \mathrm{ml}-1$ mecillinam; "S/R", plating efficiency of $1 \%$ in the presence of $10 \mu \mathrm{g} \mathrm{ml}^{-1}$ mecillinam.

b"Cit" is $10 \mathrm{mM}$ citrate, "Asc" is $10 \mathrm{mM}$ ascorbate and "Dip" is $0.25 \mathrm{mM}$ dipyridyl; addition of $0.1 \mathrm{mM} \mathrm{FeCl}_{3}$ gave the same results as ascorbate.

${ }^{c}$ The parental strain was CF6301 ( $\Delta$ relA); the same results were obtained with derivatives of DV310 ( $\Delta$ relA $)$. 
Table 4. Iron starvation in enterochelin mutants

Growth on plates

M9 glucose Casaminoacids

LB

\begin{tabular}{|c|c|c|c|c|c|c|}
\hline Strain & - & $+\operatorname{Dip}^{a}$ & - & $+\operatorname{Dip}^{a}$ & $+\mathrm{Mec}^{a}$ & $+\operatorname{Dip} \operatorname{Mec}^{a}$ \\
\hline Parental $^{b}$ & + & + & + & + & - & - \\
\hline fes::cat & + & - & + & + & - & + \\
\hline fepB & + & - & + & + & - & - \\
\hline entB & + & - & + & + & - & - \\
\hline fes::cat fepB & + & - & + & + & - & - \\
\hline fes::cat entB & + & - & + & + & - & - \\
\hline fur fes::cat & + & - & + & + & - & + \\
\hline$\Delta$ spoT & + & $\pm c$ & + & $\pm c$ & - & - \\
\hline$\Delta$ spoT fes::cat & - & - & + & - & - & - \\
\hline$\Delta$ spoT fes::cat ent $B$ & - & - & + & - & - & - \\
\hline
\end{tabular}

a"Dip" is $0.25 \mathrm{mM}$ dipyridyl, "Mec" is $10 \mu \mathrm{g} \mathrm{ml}^{-1}$ mecillinam.

${ }^{b}$ The parental strain was CF6301 ( $\Delta$ relA).

${ }^{c}$ Microcolonies visible only after two days' incubation. 
Table 5. Bacterial strains

$\begin{array}{lll}\text { Strain Genotype } & \text { Origin or reference }\end{array}$

MG1655 Wild type

CF1742 As MG1655, relA1

DV206 As MG1655, lacIpoZ $\Delta(\mathrm{Mlu})$

DV352 As DV206, P1rrnB::lacZ

CF6301 As DV206, $\Delta$ relA251::kan P1rrnB::lacZ

DV310 As DV206, $\Delta$ relA 251::kan fiu::lacZ

DV301 As CF6301, fes::cat

DV311 As DV310, fes::cat

DV377 As CF1742, fes::cat

CF1693 As MG1655, $\Delta$ relA251::kan $\Delta$ spoT207::cat

XL1 Blue endA1 hsdR17 $\left(\mathrm{r}^{-}, \mathrm{mk}^{+}\right)$supE44 thi-1 recA1 gyrA96 relA1 $\Delta$ lac/F' proAB $^{+}$lacI9 lacZDM15 Tn10
(Bachmann, 1996)

M. Cashel, lab collection

(Vinella et al., 2000)

This work

(Vinella et al., 2000)

This work

This work

This work

This work

(Xiao et al., 1991)

(Bullock et al., 1987) 


\section{Figure Legends}

Fig. 1. Enterochelin secretion in the presence and absence of ppGpp. Bacteria were spotted on a CAS plate and incubated for 48 hours. The wild type strain is DV352; the other strains are CF6301 and its derivatives, as in Table 2A.

Fig. 2. Increase of the ppGpp pool induced by dipyridyl. Strain DV301 (fes::cat $\Delta$ relA) was grown in MOPS medium containing glucose, all 20 amino acids (40 $\mu \mathrm{g} \mathrm{ml}^{-1}$ each), $1 \mu \mathrm{M}$ $\mathrm{FeSO}_{4}$ and ${ }^{32} \mathrm{P}_{\mathrm{i}}$. At time zero, dipyridyl $(0.25 \mathrm{mM})$ was added to a portion of the culture and the ppGpp and GTP pools and optical density were monitored. Squares: no dipyridyl; diamonds: + dipyridyl.

Fig. 3. ppGpp pool increase induced by iron depletion. Strain DV301 (ArelA fes::cat) was grown at $37^{\circ} \mathrm{C}$ in MOPS medium supplemented with glucose $(0.2 \%)$, all 20 aminoacids (40 $\mu \mathrm{g} \mathrm{ml}{ }^{-1}$ each $), \mathrm{P}_{\mathrm{i}}(0.3 \mathrm{mM})$ and $\mathrm{FeSO}_{4}(1 \mu \mathrm{M})$ to $\mathrm{OD}_{600}=0.5$, then diluted 250 -fold in the same medium but lacking iron and containing ${ }^{32} \mathrm{P}_{\mathrm{i}} . \mathrm{FeSO}_{4}(50 \mu \mathrm{M})$ was added to part of the culture after $5 \mathrm{~h}$ incubation (time zero in Panel A) or after $14 \mathrm{~h}$ incubation (time zero in Panel B). Squares: no addition of $\mathrm{FeSO}_{4}$; diamonds: addition of $\mathrm{FeSO}_{4}$.

Fig. 4. $\beta$-galactosidase activity on plates of the fes mutant (diamonds) and its $f e s^{+}$parent (squares) as a function of time of incubation of the plates. Upper Panel: fiu::lacZ; lower panel: $\mathrm{P} 1_{r r n B}:$ :lacZ. 
Fig. 1

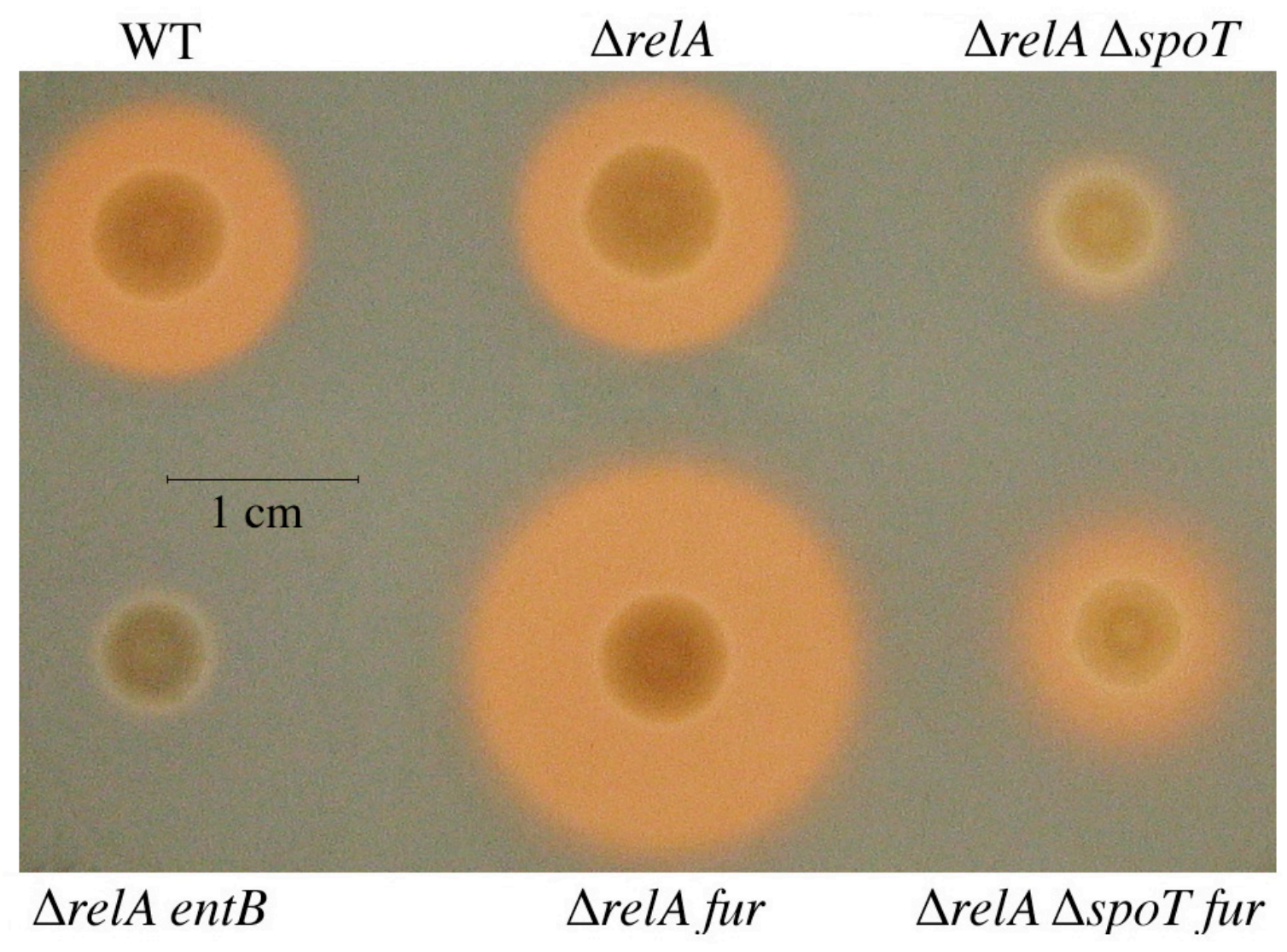


FIG. 2

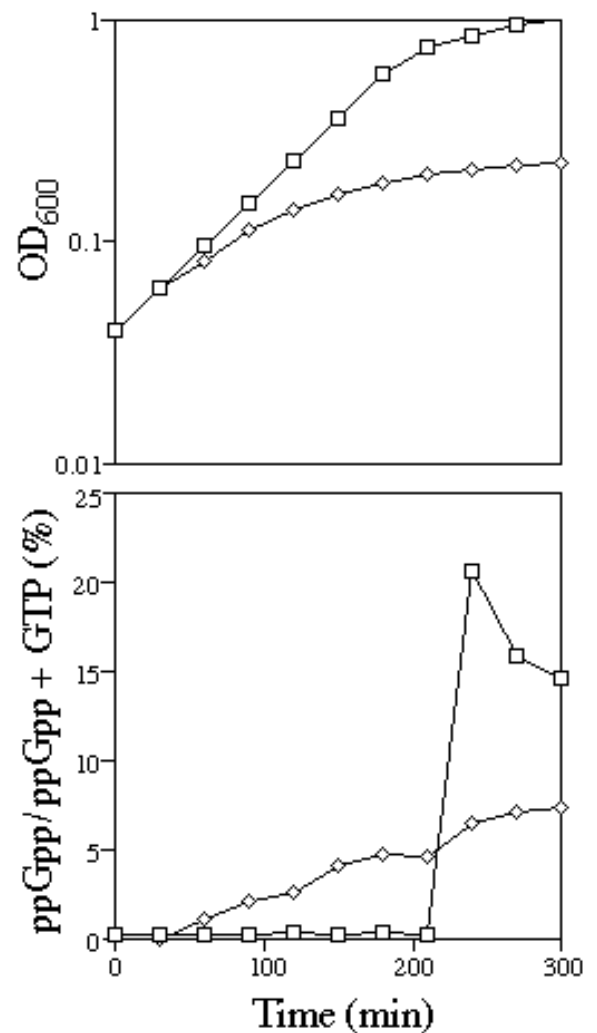

FIG. 3

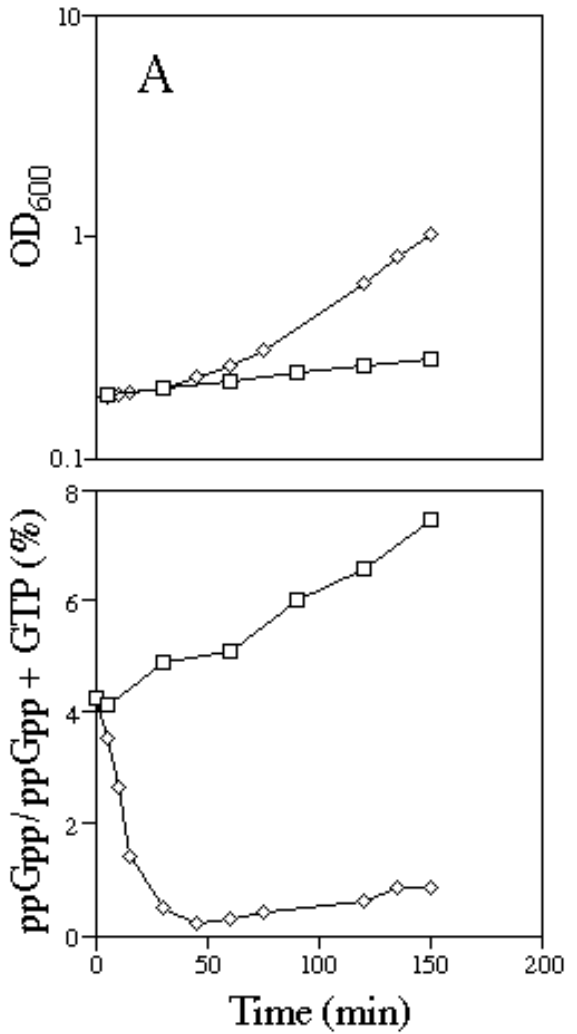

FIG. 4

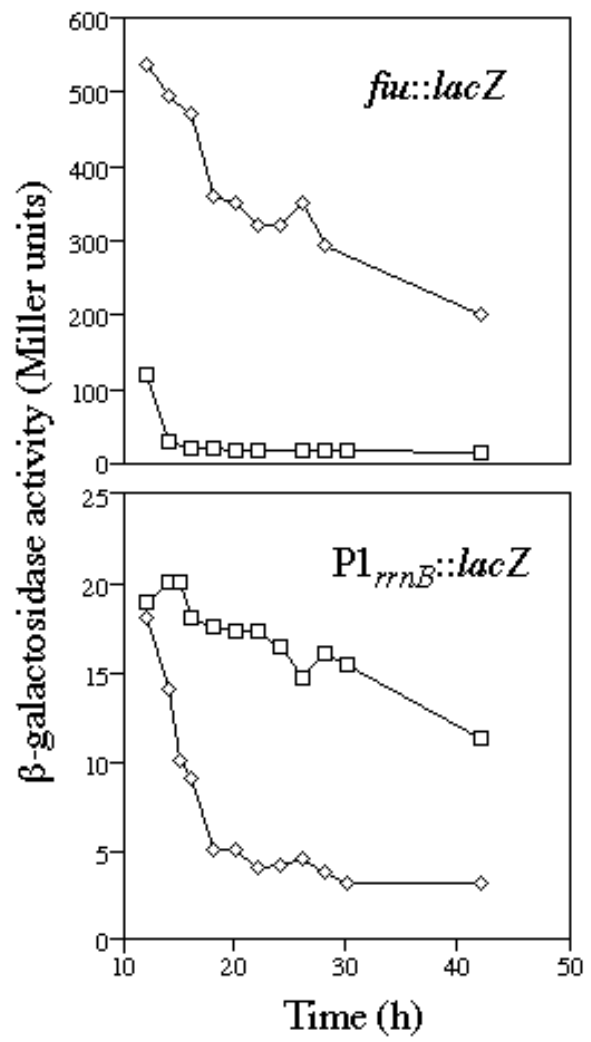

